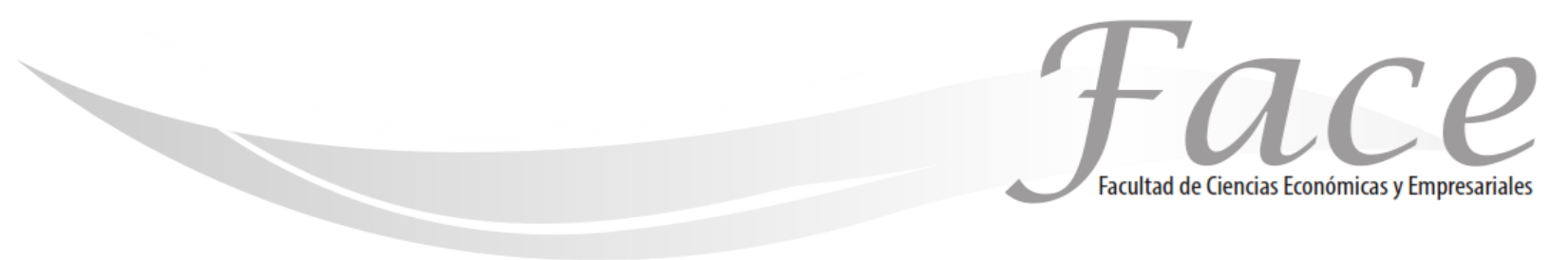

ISSN Impreso: 1794-9920 ISSN Electrónico: 2500-9338

Volumen $16-\mathrm{N}^{\circ} 1$

Año 2016

Págs. 72 - 86

\title{
LA GLOBALIZACIÓN ECONÓMICA: IMPACTO EN EL TEJIDO HUMANO
}

\author{
Luis Manuel Palomino Méndez * \\ Enlace ORCID: http:// orcid.org/0000-0002-1632-2800 \\ Elio Daniel Serrano Velasco ** \\ Enlace ORCID: http:// orcid.org/0000-0002-2356-5800 \\ Edwin Omar Jaimes Rico*** \\ Enlace ORCID: http:// orcid.org/0000-0003-3865-5208
}

Fecha de Recepción: 19 de Enero 2016

Fecha de Aprobación: 29 de Abril 2016

\section{Resumen:}

El presente artículo tiene como propósito hacer un análisis de la Globalización Económica, desde sus postulados teóricos, como causas y su impacto en la dinámica socio-económica del tejido humano como consecuencia. En este proceso histórico se permea todas las actividades económicas y sociales que se ha construido, dentro de un orden político social, en el que están inmersas todas las organizaciones, que genera la red de convivencia, que sustenta, el orden, sobre el cual se desarrolla la plantación de actividades, tendientes a la consecución de objetivos, buscando mejorar la calidad de vida de una comunidad, en una región determinada, donde impactan variables controlables y no controlables, como las comunicaciones, el comercio, la ideología política y religiosa, la tecnología, la cultura, movilidad de las personas, los recursos financieros y comerciales.

Palabras Claves: Duda Genuina, Práctica Profesional, Creencias

\footnotetext{
* Docente Tiempo Completo, adscrito al Departamento de Administración de la Universidad de Pamplona. Contacto: Luismanuel@unipamplona.edu.co

** Docente Tiempo Completo, adscrito al Departamento de Administración de la Universidad de Pamplona. Contacto: feconomica@unipamplona.edu.co

*** Docente Tiempo Completo Ocasional, adscrito al Departamento de Administración de la Universidad de Pamplona. Contacto: feconomica_distancia@unipamplona.edu.co
} 


\title{
ECONOMIC GLOBALIZATION: IMPACT ON HUMAN TISSUE
}

\begin{abstract}
:
The purpose of this article is to analyze the economic globalization from its theoretical postulates, its causes and impact on the socio-economic dynamics of human tissue. In this historical process all economic and social activities that have been built within a social political order, in which all organizations are immersed, generating a coexistence network that supports order on which different activities are developed, aimed at achieving objectives, seeking to improve the quality of life of a community in a specific region, where controllable and uncontrollable variables such as communications, trade, political and religious ideology, technology, culture, mobility of people, financial and commercial resources have a direct impact.
\end{abstract}

Keywords: La globalización económica, Tejido humano, calidad de vida, las variables controlables, Variables no controlables.

\section{GLOBALIZAÇÃO ECONÔMICA: IMPACTO SOBRE TECIDO HUMANO}

\begin{abstract}
Resumo:
Este artigo tem como objetivo analisar a globalização econômica, a partir de seus postulados teóricos, como causas e seu impacto sobre a dinâmica socioeconômica do tecido humano, como resultado. Neste processo histórico todas as atividades económicas e sociais que foi construído dentro de uma ordem social e política, na qual estão incorporadas todas as organizações, o que gera uma rede de convivência, que suporta, permeia a ordem em que desenvolve as diferentes atividades que visem objetivos, procurando melhorar a qualidade de vida de uma comunidade, em uma região onde impactam as variáveis controláveis e incontroláveis, como as comunicações, comércio, política e ideologia religiosa, tecnologia, cultura, mobilidade das pessoas, recursos financeiros e comerciais.
\end{abstract}

Palavras-Chave: Globalização Econômica, Tecido humano, Qualidade de Vida, Variáveis Controláveis e Incontroláveis. 


\section{INTRODUCCIÓN:}

La globalización parte del supuesto esencial que cada vez más estados están generando dependencias, para su sostenibilidad, propiciando escenarios para facilitar el intercambio, principalmente de recursos naturales, tecnología, conocimiento y dinero para inversión.

Los efectos de integración se pueden ver desde dos variables, la primera, el nivel sistémico, es decir, la complejidad del proceso comprometidos para el intercambio con otros estados y la segunda, las condiciones internas, que se establecieron para articular el intercambio o aproximaciones sub-sistémica, donde se evalúan las variables de crecimiento y desarrollo, las más importantes para los indicadores sociales. En la actualidad el proceso de globalización desde lo económico se mira desde dos aspectos: El primero, la estructura del sistema económico mundial, y la segunda la evolución de los mecanismos que soportan la logística del intercambio.

Estos temas se pueden visualizar a partir de la teoría de la Globalización, basados en los conceptos de desarrollo, donde interviene de manera importante, los cambios sociales, políticos, del nivel de producción local y extranjera. La base conceptual de la teoría de la globalización, es la necesidad de generar un mayor grado de integración entre los estados para un eficiente intercambio económico, evaluado con la herramienta de la balanza comercial, en donde se establece que productos y en qué cuantía de unidades y monetarias es el intercambio, para conocer el grado de beneficio.

La Globalización tiene varias aristas, que busca integrar estados, y continentes, a partir del hecho de conseguir la manera de relación socio-económica, la satisfacción de un tejido social en una región determinada.

\section{MARCO TEORICO:}

Definición de Globalización Económica, para empezar a desarrollar el tema, se hace necesario tener clara la definición de la globalización económica, por lo tanto a continuación se relacionan algunas definiciones:

La globalización o mundialización, para el economista y escritor español Sampedro (2002) la define como la constelación de centros con fuerte poder económico y fines lucrativos, unidos por intereses paralelos, cuyas decisiones dominan los mercados mundiales, especialmente los financieros, usando la más avanzada tecnología y aprovechando la ausencia o debilidad de medidas reguladoras y de controles públicos. La globalización es a menudo identificada como un proceso dinámico producido principalmente por las sociedades que viven bajo el capitalismo democrático o la democracia liberal, y que han abierto sus puertas a la revolución informática, llegando a un nivel considerable de liberalización y democratización en su cultura política, en su ordenamiento jurídico, económico nacional y en sus relaciones internacionales.

Por su parte Amschool.edu.sv (2011), escribe que la globalización económica consiste en la creación de un mercado mundial en el que se suprimen todas las barreras arancelarias para permitir la libre circulación de los capitales: financiero, comercial y productivo. El capital financiero, es el dinero, los préstamos y créditos internacionales y la inversión extranjera. Su característica es que no ocupa un lugar determinado y que gracias a la tecnología puede trasladarse de un lugar a otro con rapidez. El capital productivo, lo constituyen el dinero invertido en materias primas, bienes de capital (maquinaria, herramientas, edificios, terrenos, vehículos,...) y la mano de obra. El capital comercial, son los bienes y servicios que finalmente se compran y se venden en el mercado internacional. En este mercado internacional, los principales vendedores son las empresas multinacionales como por ejemplo: la Shell, la Coca Cola, Sony, IBM, Unilever, Phelps Dodge. Los compradores son las poblaciones de cada país y también hay muchísimos vendedores de su fuerza de trabajo, estos son los que constituyen la mano de obra, ya que ellos venden su fuerza de trabajo a cambio de un salario. La globalización entonces, vendría a ser como la etapa de culminación del proceso histórico de expansión del capitalismo, con dos objetivos: la libre movilidad del capital y la creación de un solo mercado mundial.

Agüero (2013), escribe que la globalización económica es, el intercambio comercial, cultural y tecnológico, dado entre países y bloques de estados, en donde el fin ultimo es conseguir de lo que se carece.

Para la Comisión Económica para américa Latina y el Caribe (CEPAL), el mundo de hoy está marcado por lo que se conoce como el proceso de globalización, es decir, la creciente gravitación de los procesos económicos, sociales y culturales de carácter mundial sobre aquellos de carácter nacional o regional. 


\section{LA GLOBALIZACIÓN ECONÓMICA: IMPACTO EN EL TEJIDO HUMANO}

Luis Manuel Palomino Méndez - Elio Daniel Serrano Velasco - Edwin Omar Jaimes Rico

El Banco Mundial, define la Globalización Económica, como la estrategia de desarrollo económico de los países pobres a partir del intercambio comercial.

Está claro después de leer las anteriores definiciones, que la globalización económica es una variable que no se generó sola, sino que es la resultante del desarrollo de escenarios planificados 0 no, pero que se dieron principalmente por la cultura y la tecnología que estableció las bases de herramientas que facilitaron la comunicación, entre personas y estados.

La globalización no es nueva, es un proceso de varios años, comenzando desde la era en el que el ser humano comenzó a poblar el planeta, y he aquí la primera característica, de la globalización, que es la movilidad del ser humano, su deseo de conquista y descubrimiento, facilito conocer y crear nuevas culturas, que permitieron el intercambio a pequeña escala, pero al fin y al cabo, se estaba dando los primeros pasos del comercio global, y esto es entendible, en términos de que cada cultura en una región determinada paso de ser nómada a tener un espacio fijo, en donde se poseían unos recursos pero carecían de otros, según sus propósitos culturales, en donde está inmersa las costumbres, y el estilo de vida.

Es así como para cada etapa del desarrollo humano, bajo el mismo principio, de satisfacer las necesidades, de manera civilizada o a través de guerras, el fin último es contar con los recursos necesarios que requiere una comodidad para tener calidad de vida, es más una de las razones según los historiadores, que genero en la llegada de los europeos al continente Americano fue la búsqueda de caminos que permitiera el intercambio, de productos que tenían, una alta demanda (las especias) en el viejo continente.

Con el desarrollo de las ciencias sociales, impulsado por la era industrial, se dio inicio a la productividad, creación de productos a gran escala para satisfacer las necesidades de la comunidad propia y vender a los demás, para obtener una renta económica que permitirá, obtener unas ganancias, hasta llegar a la teoría económica del Neoliberalismo. Originalmente el neoliberalismo era una filosofía económica surgida entre los eruditos liberales europeos en la década de 1930 que trataban de encontrar un "tercer camino» o un "camino entre medias» de la disputa que en ese momento se libraba entre el liberalismo clásico y la planificación económica.
El impulso de desarrollar esta nueva doctrina surgió del deseo de evitar nuevos fracasos económicos tras la Gran depresión y el hundimiento económico vivido en los primeros años de la década de 1930, fracasos atribuidos en su mayoría al liberalismo clásico. En las décadas siguientes la teoría neoliberal tendió a estar en contra de la doctrina laissez-faire del liberalismo, promoviendo una economía de mercado tutelada por un Estado fuerte, modelo que llegó a ser conocido como la economía social del mercado.

Ezcurra (1998), argumenta que el Neoliberalismo da relevancia a este modelo económico a través de la historia de las últimas décadas, ha buscado adaptarse a los requerimientos de la política social-económicas, señala que es un paradigma cambiante y como el Banco Mundial es el gran motor que impulsa la teoría económica del Neoliberalismo, en donde desde inicios de los 90's, llevó adelante una reformulación del modelo de "crecimiento con orientación de mercado" impulsado durante los años 80 en el Sur y posteriormente en Europa oriental. Por ejemplo, revisó el vínculo Estado/mercado y, también, aceptó que el crecimiento económico per se resulta insuficiente para el logro de mejoras sociales. En ese marco, empezó a reivindicar la importancia de un patrón de crecimiento intensivo en trabajo (crecimiento con empleo), consintió cierta intervención pública con fines distributivos y jerarquizó las denominadas "políticas sociales".

Por ende, hubo cambios. Es decir, aquella revisión no constituyó (ni implica) una mera salida retórica. Además, configuró una reacción. 0 sea, una respuesta a la explosión de la pobreza y la desigualdad que tuvo lugar en el Sur durante los 80's, década de implantación de los "ajustes estructurales". En definitiva, conformó un esfuerzo por neutralizar los riesgos políticos que tal deterioro social supuso, la analista desarrolla e interpreta las modificaciones que se dieron para llegar a la década de los 90's, con las llamadas "reformas de segunda generación" impulsadas por la banca de Bretton Woods y, en particular, por el Banco Mundial que consistieron en las Ideas-Fuerza, que son, una herramienta de la comunicación en la que, el emisor quiere implantar una idea a través de un mensaje, traslado esto a lo económico, es mostrar los beneficios del modelo, a partir de los beneficiarios y como todos pueden llegar a serlo, para Ana María Esquerra, es más los problemas, que el Neoliberalismo ha traído, desde el sesgo dado por las grandes potencias mundiales, en donde estas desde este modelo económico se benefician mas, que los países denominados en vía de desarrollo, principalmente por las desigualdades, en infraestructura para competitividad en igualdad. 
La CEPAL en el tema de la globalización y el desarrollo analiza el escenario de la globalización en el marco del Neoliberalismo como la suma de estrategias nacionales que deben diseñarse para entrar en los requisitos que exige una mayor incorporación a la economía mundial. Pero también advierte sobre la problemática o riesgos que el proceso plantea originados en nuevas fuentes de inestabilidad, tanto comercial como, especialmente, financiera. Este organismo ve como principales riesgos, la exclusión de aquellos países que no están adecuadamente preparados para las fuertes demandas de competitividad propias del mundo contemporáneo, y riesgos de acentuación de la heterogeneidad estructural entre sectores sociales y regiones dentro de los países que se integran, de manera segmentada y marginal, a la economía mundial. Muchos de estos riesgos obedecen a dos características preocupantes del actual proceso de globalización. La primera es el sesgo que se aprecia en la globalización de los mercados: junto a la movilidad de los capitales, los bienes y los servicios, y todo lo anterior para la CEPAL, lo más preocupante es la ausencia de una gobernabilidad adecuada para el mundo de hoy, no sólo económica -como se ha hecho particularmente evidente en el campo financiero- sino también en muchos otros terrenos, debido al enorme contraste entre los problemas de alcance mundial y los procesos políticos, que siguen teniendo como marco las naciones.

El capital financiero, según la CEPAL, es el dinero, los préstamos y créditos internacionales y la inversión extranjera. Su característica es que no ocupa un lugar determinado y que gracias a la tecnología puede trasladarse de un lugar a otro con rapidez.

El capital productivo, lo constituyen el dinero invertido en materias primas, bienes de capital (maquinaria, herramientas, edificios, terrenos, vehículos, entre otros) y la mano de obra. El capital comercial, son los bienes y servicios que finalmente se compran y se venden en el mercado internacional. Bajo esta premisa expuesta por la CEPAL, se ve claramente el favorecimiento de los países 0 bloques de estados que tienen unas economías fuertes apalancadas en el nivel de productividad con tecnología de punta. Elemento, bajo las anteriores apreciaciones, es que los países no plenamente desarrollados, solo aportan al intercambio comercial mundial, recursos, minerales principalmente, con consecuencias ambientales, como ejemplo, para el caso colombiano, lo que está sucediendo en el Casanare, uno de los departamentos con mayor producción petrolera en Colombia, con un nivel de extracción de 600.000 barriles diarios de petróleo, se ha generado una sequía que afecta otros sectores económicos de la región, agro-industriales, como el arroz, la ganadería y la leche, que trae como resultado desempleo, y principalmente carencia de productos de primera necesidad para la comunidad de la región.

La CEPAL, las teorías económicas neoclásicas acentúan la preeminencia de las ventajas comparativas (Klein, Pauly y Voisin 1985), los métodos propios de las relaciones internacionales resaltan las variables geopolíticas (Keohane 1993, y Thompson 1991), mientras que las perspectivas desde la teoría de los sistemas mundiales subrayan los intercambios desiguales (Amin 1989; Frank 1979; Wallerstein 1991). Estas aproximaciones ofrecen contrastes en las interpretaciones del cambio a nivel mundial

La globalización entonces, vendría a ser como la etapa de culminación del proceso histórico de expansión del capitalismo, con dos objetivos: la libre movilidad del capital y la creación de un solo mercado mundial.

Con respecto a la primera se le denomina capital golondrina, a aquel capital financiero en manos de inversionistas, que vigilan el mercado en general y a escala mundial, para hacer inversiones, teniendo en cuenta variables, como tasas de cambio, beneficios tributarios, estabilidad política, y datos históricos de consumo. Y, la segunda, que es la creación de un Mercado Mundial, a través del fortalecimiento la economía de escala, una única moneda, la eliminación de aranceles, en donde el estado como tal, no tiene ninguna influencia, y las grandes empresas multinacionales pasan a delinear todo el contexto en el que se mueve el ser humano.

El Banco Mundial define el Desarrollo económico. Cambio cualitativo y reestructuración de la economía de un país en relación con el progreso tecnológico y Sociales. El principal indicador del desarrollo económico es el aumento del PNB per cápita (o PIB per cápita), que refleja el incremento de la productividad económica y del bienestar material, como promedio, de la población de un país.

Para la CEPAL, el desarrollo económico, tiene que ver con el crecimiento de una economía a partir de la igualdad y la sostenibilidad a largo plazo y hace una división del desarrollo económico en cinco áreas fundamentales:

1. La conservadora, seguida principalmente por los economistas neoclásicos;

2. La reformista, seguida por los keynesianos;

3. La revolucionaria productiva, por el marxismo tradicional; 


\section{LA GLOBALIZACIÓN ECONÓMICA: IMPACTO EN EL TEJIDO HUMANO}

Luis Manuel Palomino Méndez - Elio Daniel Serrano Velasco - Edwin Omar Jaimes Rico

4. La revolucionaria humana, en torno a economistas del desarrollo humano e izquierdistas actuales (alter-globalitas, ecologistas y feministas); $y$,

5. la revolucionaria personal, por un heterogéneo conjunto de economistas perennes 0 transpersonales con antecedentes teóricos en el anarquismo político clásico. Estas visiones responden las cuestiones básicas de la economía, el desarrollo y la desigualdad entre economías fuertes y economías débiles.

Dados los diferentes análisis, y teorías que articulan la globalización como un resultado de una estrategia, se ha comenzado a formular la Globalización como una teoría de desarrollo, que integra y permea, todas las variables inmersas en el sistema y las que no están directamente relacionadas, pero que día a día, son jalonados bajo la dinámica, del significado del término.

La CEPAL, tiene dos significados principales, que a continuación se relacionan

1. Como un fenómeno, implica que existe cada vez más un mayor grado de interdependencia entre las diferentes regiones y países del mundo, en particular en las áreas de relaciones comerciales, financieras y de comunicación;

2. Como una teoría del desarrollo, uno de sus postulados esenciales es que un mayor nivel de integración está teniendo lugar entre las diferentes regiones del mundo, y que ese nivel de integración está afectando las condiciones sociales y económicas de los países.

Los niveles de mayor integración que son mencionados por la globalización tienen mayor evidencia en las relaciones comerciales, de flujos financieros, de turismo y de comunicaciones. Además de las relaciones tecnológicas, financieras y políticas, los académicos de la globalización argumentan que importantes y elementos nunca antes vistos de comunicación económica están teniendo lugar entre naciones. Esto se pone de manifiesto preferentemente mediante novedosos procesos tecnológicos que permiten la interacción de instituciones, gobiernos, entidades y personas alrededor del mundo.

Otro concepto, ha salido para acompañar la globalización, en el entorno del desarrollo económico, y es el desarrollo sostenible, definido como aquel capaz de satisfacer las necesidades actuales sin comprometer los recursos y posibilidades de las futuras generaciones. Esta definición es la del informe de la Comisión Brundlandt. La señora Brundlandt es la primera ministra de Noruega y el año de 1990 recibió el encargo de la ONU de redactar un primer informe para preparar la Cumbre de la Tierra de Río de Janeiro, dos años más tarde.
Hay otras definiciones también interesantes como la que proponen D. Pearce, A. Markandya y E.B. Barbier, en la cual se establece que en una sociedad sostenible no debe haber:

- $\quad$ un declive no razonable de cualquier recurso

- un daño significativo a los sistemas naturales

- un declive significativo de la estabilidad social

Se debe tener en cuenta, que se trata de una definición estratégica de carácter conceptual y globalizadora, y se produce una notable dificultad al traducirla al día a día. Sin embargo, hay que hacer un esfuerzo para superar las dificultades de orden práctico que supone el principio ecologista del pensar globalmente y actuar localmente.

Principales retos que plantea el desarrollo sostenible.

La incapacidad de la especie humana para vivir en armonía con el planeta, la gran interacción entre el hombre y el sistema natural, son los grandes problemas medio ambientales de hoy. Hasta nuestros días, ninguna especie, excepto el hombre, ha conseguido modificar tan substancialmente, en tan poco tiempo, las características propias del planeta.

Así, se plantean los grandes problemas planetarios siguientes:

- Superpoblación y desigualdades

- El incremento del efecto invernadero

- Destrucción de la capa de ozono

- Humanización del paisaje

- Preservación de la biodiversidad

- La erosión, la desertización y la destrucción de la selva

Y a escala local:

- El sistema productivo

- El agua

- Los residuos domésticos

- Suministro energético

- El sistema de transportes

Para entender las implicaciones del Neoliberalismo en todas las variables socio-culturales, se describe sus efectos, comenzando cómo se impuso: Aprovechando la poca eficiencia del estado en el manejo de la economía, critica bien merecida, por los desajustes generados en desigualdades y el desacelere del aparato productivo y la lógica consecuencia del desempleo y por ende la pobreza, en un estado incapaz de producir bienes y servicios y en 
donde un mercado solo puede adquirir estos inmersos en una oferta y una demanda, lo que trae la consecuencia de

garantizar no sólo el uso más productivo de los factores de la producción, sino también producir los bienes y servicios socialmente necesarios en la cantidad y calidad con que los consumidores los demandan y de esta manera el mercado mismo se equilibra sin la necesidad del estado, los críticos de la injerencia del estado tenían entre sus banderas de controversia frases como las siguientes: el pueblo preferible sacrificar la democracia al bienestar de la población ("el pueblo quiere comer y luego ser libre").

El pensamiento único, fue un avance del neoliberalismo y se toma como un cambio ideológico, que tiene como finalidad provocar el conformismo social, basado en los valores del mercado, la competencia, la ganancia y el capital, generando la ausencia del debate político, económico y social, remplazado por la exaltación del capitalismo como único medio de satisfacer el tejido social, con la consecución de los recursos requeridos, en el marco de lo social-político, se articuló el capitalismo con la democracia su promotor Francis Fukuyama (1994: 83), escribe al respecto de manera enfática y dogmática: En tiempos de nuestros abuelos, muchas personas razonables podían prever un futuro socialista radiante, en el cual habían de ser abolidos la propiedad privada y el capitalista, y en el que se habría sobrepasado, en cierto modo la política. Hoy, en cambio, nos cuesta imaginar un mundo que sea radicalmente mejor que el nuestro, o un futuro que no sea esencialmente democrático y capitalista.

La construcción de este imaginario burgués, particularmente correspondiente a las clases medias con pretensiones económicas e intelectuales pero incapaces de rebasar los límites del consumidor acrítico, de ninguna manera ha sido obra del azar sino resultado de un proyecto tendiente a "manufacturar el consenso", al cual se le han destinado multimillonarios recursos encaminados a manipular los medios masivos de comunicación con el fin de producir un duradero lavado de cerebro que permita la imposición, sin oposición consistente, de políticas promovidas para alentar los valores mercantiles y en beneficio sólo de la hegemonía del capital, aunque parezcan preocupadas y orientadas por el bien común, del que por cierto dice William Blake: "Es la aspiración del hipócrita y del bribón." (Glockner, 2002: 28.).

Además, el pensamiento único peculiar del neoliberalismo, dice Stefanía (2002: 49), se sostiene en otras "verdades" como las siguientes: "El liberalismo económico lleva inexcusablemente a la democracia; 0 bien, hay que adoptar el modelo neoliberal, que se impone en todo el mundo!"; también: "La intervención del Estado en el mercado, pertenece al pasado sus defensores son dinosaurios ideológicos". Una "verdad" más, ésta impuesta tanto por el BM como por el FMI, es aquella que proclama

la entrega de los recursos naturales al capital extranjero como la única solución posible al atraso de las economías emergentes.

Los ideólogos y promotores del Neoliberalismo, lograron permear, todos los organismos internacionales para convencer, de que este modelo económico, es el único capaz de generar calidad de vida, desde su propuesta de intercambio comercial, para una competencia que busque, incrementar niveles de productividad, bienes y servicios de calidad, sin la intervención del estado, sino con un mercado direccionado desde la oferta y la demanda.

La propuesta anterior, según la CEPAL, genero una confrontación entre el estado y las Mega corporaciones, en donde, los pensadores suponen la existencia de un estado generador de condiciones para el expansionismo del capitalismo.

Desde el punto de vista de los autores, lo que se busca, es el total proteccionismo de las grandes corporaciones, a expensas de un estado manipulado, si se mira con detenimiento, por lo menos en las democracias de América Latina, los grandes multinacionales, son las aportantes mayoritarias en la campañas presidenciales, estableciéndose un compromiso, que se ve, en las legislación de normas que favorecen plenamente el funcionamiento de estas multinacionales.

Michael Porter (1990: 18): afirma que "El papel correcto del gobierno es el de catalizador y estimulador. Es el de alentar -o incluso empujar- a las empresas a que eleven sus aspiraciones y pasen a niveles más altos de actuación competitiva". Siendo así, el estado tiene una gran participación, y controla de alguna manera el mercado, partiendo del estímulo que el mismo gobierno da a algunas multinacionales.

Petras (2003): dice que las mega corporaciones de origen estadounidense tienen una gran relevancia en el mundo: "El valor de las compañías estadounidense excede el valor combinado de todas las demás regiones. La valoración de las trasnacionales estadounidense es de 7 billones 445 mil millones de dólares, contra 5 billones 141 mil millones de dólares" de las restantes de todas las demás nacionalidades Las trasnacionales estadounidenses dominan la lista de las 500 principales empresas del mundo, casi la mitad de las mayores trasnacionales (48 por ciento) son de propiedad y dirección estadounidense, casi el doble del competidor regional más próximo, Europa, con 


\section{LA GLOBALIZACIÓN ECONÓMICA: IMPACTO EN EL TEJIDO HUMANO}

Luis Manuel Palomino Méndez - Elio Daniel Serrano Velasco - Edwin Omar Jaimes Rico

28 por ciento La concentración del poderío económico es aún mayor si se analiza las principales 50 trasnacionales, de las cuales 60 por ciento son de propiedad estadounidense, y es todavía más evidente al examinar las 20 mejor situadas, de las cuales más de 70 por ciento son de ese país. De las primeras 10, Estados Unidos controla 80 por ciento.

Como se puede ver la CEPAL, no es una convencida plena de este modelo, y más aun cuando sostiene, que en América Latina, el Neoliberalismo genero tres grandes problemáticas que son:

\section{Inestabilidad económica, acompañada de bajas tasas de} crecimiento;

\section{Aumento social y regional de la pobreza;}

3. Mayor dependencia y creciente pérdida de soberanía nacional.

Agrega la CEPAL, que a lo anterior, debe sumarse la dependencia intelectual (incluida la científica y tecnológica), también se acentúa y a pesar de reconocerse que nuestros países son ahora más dependientes de lo que lo eran en los años sesenta, por una de esas paradojas del sentido común neoliberal las teorización es sobre el significado de la dependencia, o acerca del imperialismo, son hoy desestimadas por buena parte de los intelectuales orgánicos del capital, pero también incluso por académicos que las consideran anacronismos teóricos, precisamente en estos momentos cuando ambas categorías adquieren una vigencia e importancia que, a pesar de todo, no han perdido desde el tiempo de su creación.

El doctor Jaime Órnelas Delgado, es el autor del cuestionamiento, sobre el modelo del Neoliberalismo, en contexto con la CEPAL, y de donde se realizaron los comentarios, sobre la impresión del tema en el impacto actual del modelo.

\section{REFLEXIÓN:}

Uno de los postulados de los defensores del modelo es que la globalización trae consigo oportunidades igualitarias, pero los hechos lo contradicen pues hasta el momento, el proceso globalizador neoliberal en ninguna parte ha acarreado beneficios compartidos, en todo caso ha mantenido y reforzado los aspectos esenciales del capitalismo la relación de producción, por ejemplo, basada en la explotación del trabajo por el capital, cuyo desarrollo desigual significa mantener y profundizar las diferencias sociales y regionales que él mismo crea.

En este sentido, el economista egipcio Samir Amin (1999: 30), advierte que: "La expansión capitalista no implica ningún resultado que pueda identificarse en términos de desarrollo. Por ejemplo, en modo alguno implica pleno empleo, o un grado predeterminado de igualdad en la distribución de la renta."

El propio Amin, encuentra la razón de la desigualdad en el hecho de que la expansión del capitalismo se guía por la búsqueda de la máxima ganancia para las empresas, esto es, sin mayor preocupación por las cuestiones relacionadas con la distribución de la riqueza, o la de ofrecer empleo en mayor cantidad y calidad.

Por su parte, el sociólogo francés Alain Touraine (1994: 10), apelando a la historia del desarrollo capitalista es, aún, más contundente cuando escribe: La afirmación de que el progreso es la marcha hacia la abundancia, la libertad y la felicidad, y de que estos tres objetivos están fuertemente ligados entre sí no es más que una ideología constantemente desmentida por la historia. Más aún, lo que se llama el reinado de la razón, ¿no es acaso la creciente dominación del sistema sobre los actores, no son la normalización y la estandarización las que, después de haber destruido la economía de los trabajadores, se extiende al mundo del consumo y la comunicación. $Y$ no es acaso en nombre de la razón y de su universalismo como se extendió la dominación del hombre occidental, varón, adulto y educado sobre el mundo entero.

De esta manera, se puede afirmar que la expansión capitalista en su etapa de globalización neoliberal puede ser cualquier cosa menos un proceso capaz de permitir mejores niveles de bienestar para la mayor parte de la población. Si no que busca desde el paradigma de la igualdad fundamentar el mercado abierto y único, el problema está, en la desigualdad de la competencia y se ve como a través de una economía de escalas se busca llegar a todos los mercados, afectando la industria nacional, provocando desempleo y por ende pobreza.

Para terminar la problemática de la Globalización Económica, se analizará, en parte, el caso Colombiano.

En la revista Dinero (2013), el ex presidente Cesar Gaviria, explica como se dio inicio a la Apertura económica, primer paso del Neoliberalismo, para entrar en la Globalización Económica. Comenta, se expidió un nuevo documento Conpes, el 2494 del 29 de octubre de 1990, con el que puso el acelerador para sacar adelante la apertura. "Teníamos claro que íbamos a desmontar los aranceles de 
forma gradual, en un lapso de tres años y, además, el primer paso fue eliminar la licencia previa". acontecimientos adversos: la sequía de 1992, el racionamiento, la caída de los precios internacionales y, principalmente, la decisión del Banco de la República que, con su recién adquirida independencia, dejó de entregar subsidios a la producción agropecuaria. "Además, el

campo colombiano tiene un problema estructural que lo hace crecer menos que el resto de la economía, cosa que no ocurre en los países vecinos", explica.

Con o sin razón, lo cierto es que hay una verdad de a puño y Gaviria la dice sin tapujos: sin apertura, hoy el país sería muy distinto. Después de leer, el escrito de la revista Dinero, en donde el expresidentes Gaviria, cuenta como Colombia entro en la era del Neoliberalismo, se hace necesario ver los resultados de la aplicación del modelo, para lo cual se tomaran datos, del Banco de la Republica y artículos de analistas económicos, obteniendo los resultados generales de la reforma neoliberal en Colombia en los siguientes términos:

Para la CEPAL, Colombia refleja en términos generales los mismos resultados que los demás países de América Latina, la apertura e internacionalización de la economía colombiana han consolidado una serie de núcleos transnacionales de actividad económica (en manos de los grandes grupos económicos), rodeados por una periferia caracterizada por la existencia de la crisis, desintegración y estancamiento económico. en tres tramos, decidimos que lo mejor era aplicar toda la rebaja arancelaria de una vez", recuerda el expresidente, quien hoy no duda de lo acertada que fue su decisión, al confirmar los grandes cambios generados por esta decisión. Estaba y sigue convencido de que ese era el camino y la prueba es que el país continuó negociando tratados de libre comercio.

La decisión de acelerar la apertura la adoptó Gaviria luego de una charla con Nicanor Restrepo, líder en la época de suramericana, una de las compañías del poderoso Sindicato Antioqueño. Gaviria cuenta que Restrepo le pidió que no retrasaran más las medidas porque la economía estaba padeciendo la incertidumbre de una baja de aranceles con cuentagotas. "Más que una oposición a la apertura comercial, recibimos quejas porque para algunos el proceso fue muy rápido, pero creo que el error fue haber comenzado de forma gradual. Vivimos inicialmente unos resultados negativos que hubiéramos podido evitar con un desmonte arancelario inmediato. Es más, cuando se hizo toda la rebaja, la economía reaccionó y el país creció", comenta Gaviria.

Frente a la percepción de que el agro fue la principal víctima, Gaviria considera que más que la apertura, lo que afectó al campo en ese momento fue una acumulación de
En lo social, una clara consecuencia del modelo neoliberal ha sido el crecimiento del desempleo, el subempleo y la informalidad en el país. En octubre de 1998, la tasa oficial de desempleo alcanzó un $16 \%$, la cifra más alta en la historia de Colombia. Asimismo, el Informe de Desarrollo Humano de PNUD para 1997 estimó que aproximadamente el $60 \%$ de la fuerza laboral en el país está empleada en el sector informal, en donde la seguridad laboral, las garantías legales y los niveles salariales se ven seriamente recortados. El neoliberalismo también ha contribuido a niveles alarmantes de pobreza e inequidad; alrededor de $55 \%$ de la población vive por debajo del nivel de pobreza. Esta situación se ha visto agravada por la crisis del sector agrícola, también producto del programa de reforma neoliberal.

Muchos de los datos anteriores, fuera del manejo económico, hay que atribuirlos a la violencia, que no permite el desarrollo de áreas con potencialidades agrícolas. En este sentido, Stephen Gilí (1996) afirma que el proceso de globalización se ha asociado con una paradoja: la proliferación del modelo neoliberal tiene consecuencias nocivas en términos de la polarización social, pero al mismo tiempo ha sido vinculada con la 


\section{LA GLOBALIZACIÓN ECONÓMICA: IMPACTO EN EL TEJIDO HUMANO}

Luis Manuel Palomino Méndez - Elio Daniel Serrano Velasco - Edwin Omar Jaimes Rico

expansión de la democracia. En este dilema reside tal vez una de las manifestaciones más claras de los efectos contradictorios y desiguales de la globalización: por un lado, la creciente integración de los países tercermundistas a la economía global de mercado y, por el otro, la agudización de situaciones internas de inestabilidad y

desorden como resultado de la adopción de unas reformas que hicieron posible aquella integración. Esto, combinado con una "comunidad internacional" que le exige al Tercer Mundo la preservación del orden doméstico, la modernización de sus economías y la consolidación de sus democracias completa el complejo cuadro mundial al que se enfrenta Colombia en la actualidad.

Desde el gobierno del expresidente Uribe, la economía colombiana, se replanteo e impulso, varios sectores productivos que han permitido el crecimiento sostenible en el nivel de producción, en cifras cercanas al $4 \%$, de crecimiento, apoyado en la construcción, los recursos naturales, y el incremento de venta de servicios, además una fuerte inversión en la infraestructura vial, la modernización de los puertos, impulsando las exportaciones hacia nuevos mercados y explorando otros, con expectativas de alta compra,

Según estudios del BBVA Research, publicados en la revista PORTAFOLIO de Febrero 14 de 2013, "El principal catalizador de la recuperación económica será el consumo de los hogares, el cual tomará los mayores réditos de la reducción de la tasa de interés. Los indicadores de confianza de los consumidores y los comerciantes confirman la expectativa de un consumo 'más dinámico en estos dos años" afirmó Mauricio Hernández, economista de BBVA Research. Según los cálculos de la entidad, la producción diaria de petróleo llegará en 2014 hasta 1,15 millones de barriles diarios y las exportaciones de carbón crecerán entre un 14 y un 16 por ciento acumulado este y el próximo año: "El transporte se beneficiará del mayor comercio exterior. $Y$ el comercio interno tendrá una dinámica de recuperación, en línea con el panorama del consumo privado", agregó Hernández. Durante el 2013 y 2014 el desarrollo de proyectos de infraestructura que se encuentran en marcha y el mayor avance de las iniciativas regionales y locales en el segundo y tercer año de gobierno (2013 y 2014), así como las nuevas licitaciones nacionales, tendrán un papel preponderante en la creación de empleo y en el buen desempeño de la producción de cemento, hierro, vidrio y cerámica. "En el caso de la vivienda, prevemos un impulso sobresaliente de las obras comerciales y logísticas y de la vivienda de interés social, principalmente en 2014", explicó el economista de BBVA Research.
Así mismo, Colombia logrará aumentar nuevamente su tasa de inversión en el 2013 y 2014, incluso a un ritmo mayor que en el 2012, por el aporte de las obras de infraestructura, de modo que pasará de una tasa de 26,6 por ciento del PIB en el 2011 a una de 27,9 por ciento en el 2014.

De acuerdo con las perspectivas de BBVA Research, el comportamiento estimado de la economía colombiana superará el promedio de Latinoamérica, donde se espera que la región registre crecimientos cercanos al 3,6 y 3,7 por ciento en los años objeto del estudio, con los cuales la aceleración del PIB que tendrá Colombia en 2014 implicará destacarse como una de las economías con mayor expansión en la región.

Igualmente, la inflación se mantendrá por debajo de la meta ( 3 por ciento) en el 2013, con un retorno lento a partir del segundo semestre del 2013 y una convergencia al 3 por ciento en el 2014. "El tipo de cambio se apreció en 9 por ciento en el 2012, con indicios de continuar con una presión similar en el 2013. Así mismo, los amplios niveles de liquidez adicional continuarán generando presión sobre la moneda, con lo cual el tipo de cambio retornara lentamente a su valor de largo plazo cercano a los 1800 pesos", señaló Julio César Suárez, economista de BBVA Research.

En lo que respecta al Banco Central, el Emisor debería continuar con una política de reducción de las tasas de interés durante el 2013. "Esperamos que el Banco de la República revierta su postura monetaria en el segundo trimestre de 2014, respondiendo a su vez a la normalización de la actividad externa y a la moderación de la incertidumbre fiscal de los países desarrollados. La recuperación que esperamos en 2013 y del primer trimestre de 2014, deberían motivar al Emisor a revertir lentamente su postura de rebaja de tasas", sostuvo Suárez. El informe concluye que Colombia registra unas perspectivas de crecimiento positivas para los próximos años. "Los números que esperamos mantendrán al país en una posición sobresaliente a nivel de América Latina pero consideramos que la manera como se resuelvan algunos temas de política pública en los próximos años determinará que Colombia aumente su potencial de crecimiento y consolide un liderazgo económico en la región", señala el análisis.

De acuerdo con Suárez, estos años son los de las grandes definiciones donde se pondrán a prueba cambios institucionales, políticos y económicos realizados en los últimos años y se evidenciará la necesidad de realizar algunos adicionales. "Los avances en las conversaciones 
ISSN: 1794-9920 - Enero - Julio

Volumen 16 Número: 1, Año: 2016 Págs. 71 - 85

de paz son un tema que estará en la agenda pública durante 2013-14 y sus resultados podrán afectar el rumbo de algunos elementos de política pública en los próximos años. Sin embargo, otros asuntos de discusión económica serán relevantes como son el reto de avanzar en infraestructura de transporte, encontrar soluciones permanentes a los cuellos de botella de la minería y las medidas para hacer competitiva a la industria", puntualizó.

A continuación se presentan resultados de la construcción, según datos banco de la república y el departamento de estadística nacional, DANE. El primero para datos octubre del 2014, en construcción, que es un indicador importante para demostrar el movimiento económico de un país.

Licencias de Construcción - Octubre de 2014. En octubre del año 2014 se licenciaron $2.304 .708 \mathrm{~m}^{2}$ para construcción, $353.320 \mathrm{~m}^{2}$ más que en el mismo mes del año anterior $\left(1.951 .388 \mathrm{~m}^{2}\right)$, lo que significó un aumento de $18,1 \%$. Este resultado está explicado principalmente por el incremento de $11,9 \%$ en el área aprobada para los destinos no habitacionales. Fuente DANE

Tabla N ${ }^{\circ} 1$.

Indicadores económicos, Economía Colombiana, años

2013 y 2014

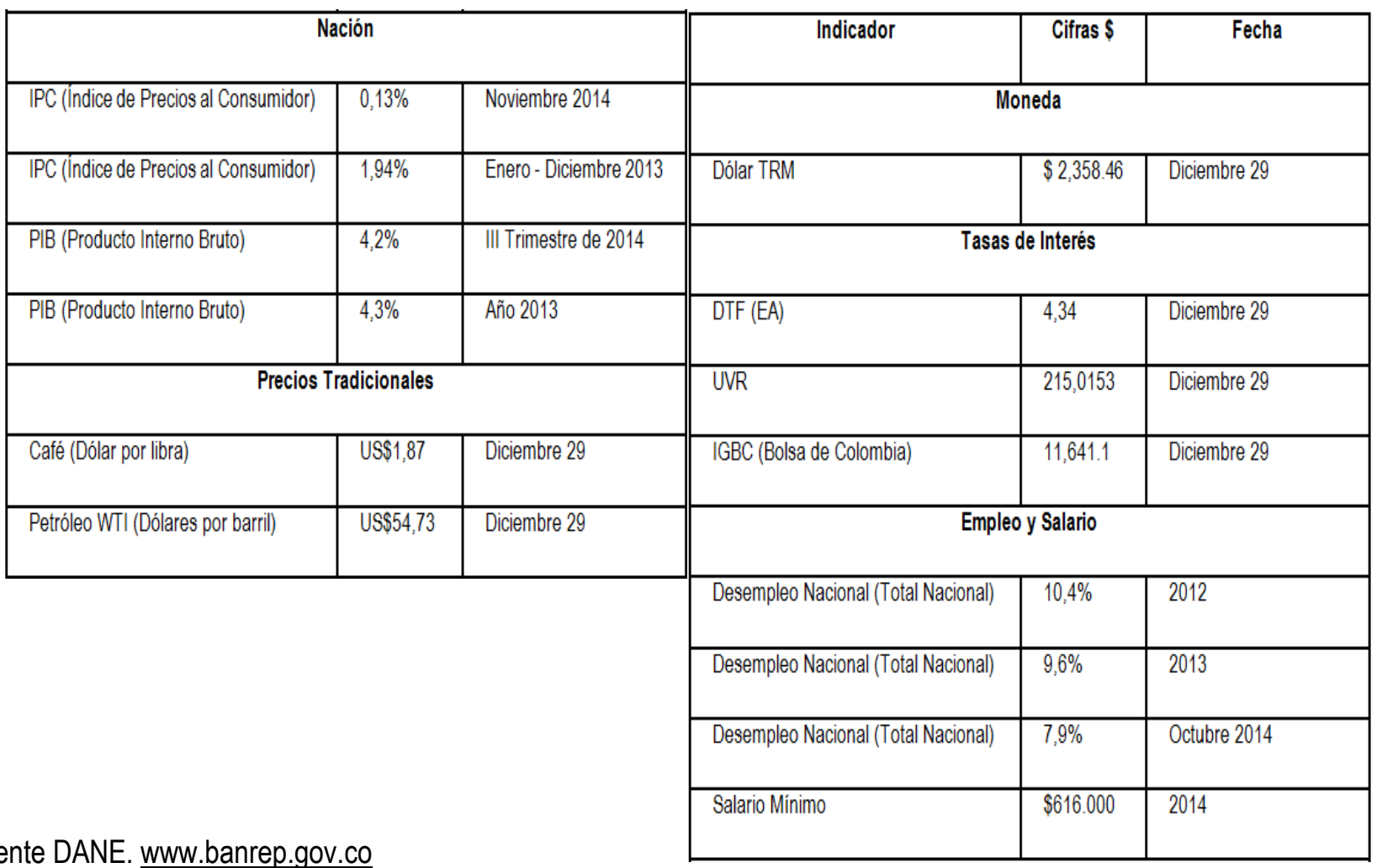




\section{LA GLOBALIZACIÓN ECONÓMICA: IMPACTO EN EL TEJIDO HUMANO}

Luis Manuel Palomino Méndez - Elio Daniel Serrano Velasco - Edwin Omar Jaimes Rico

Se puede observar, una estabilidad, en la economía, en donde la inflación, se mantiene controlada, y ya se tiene un estimado de la baja del precio del petróleo, y como el PIB, se mantiene en crecimientos representativos.

Para el año 2015, el gobierno y los analistas económicos, moderan la proyección económica, basado principalmente, por la baja en el precio del petróleo, ya que Colombia en el año 2014, alcanzó la cifra de 1400.000 barriles diarios a precio entre 90 y 110 dólares el barril. Las proyecciones económicas, están tomando el proceso de paz, como un incentivo importante para el crecimiento del país, no solo por lo que el estado invierte en la defensa, si no en la imagen negativa de incertidumbre por la violencia, que pueden ver los inversionistas extranjeros, si esto se soluciona, el país tendría más dinero para invertir, principalmente en infraestructura vial, apoyo a la pequeña empresa, la vivienda social, a la educación y salud.

Para los analistas económicos del gobierno y el sector privado están haciendo sumas y restas para calcular sus presupuestos del año entrante y ya están incorporando que el 2015 será bueno, pero no tanto como este año. En eso coinciden el Gobierno, los centros de estudios, los analistas y los gremios en distintas actividades de la producción. De hecho, las proyecciones de crecimiento para el 2015 están entre 4,2 y 4,5 por ciento, pero detrás de ese dato hay una gran variedad de historias.

Algunos indicadores siguen creando buenas condiciones. Por ejemplo, los analistas tienen la expectativa que la inflación continuará muy cerca del 3 por ciento, rango meta fijado por el Emisor. Igualmente, se espera que el mercado laboral continúe mejorando, de manera que el desempleo podría rondar el 8,5 por ciento, lo cual se traduce en una mejora en el gasto de las familias. Es justamente el consumo privado lo que, a juicio de los analistas, seguiría impulsando la economía, pues la confianza de los consumidores ha mejorado y, según el Índice Genworth realizado por Ipsos Morie, el 76 por ciento de los colombianos es optimista sobre su situación financiera.

Otro punto a favor es la inversión, tanto pública como privada. Sobre el primer punto, Credicorp Capital considera que, además del gran volumen de recursos de regalías para proyectos, "el 2015 es el último año de gobiernos locales y regionales (las elecciones de alcaldes y gobernadores se llevaran a cabo en octubre), lo que seguramente incentivará una mayor ejecución de proyectos". Y, en el frente privado, las inversiones estarán motivadas "por el inicio de nuevos proyectos productivos, por el comienzo de la primera fase de los proyectos de infraestructura $4 G$ y por una aceptable dinámica de la demanda por vivienda", dice Bancolombia. Precisamente, la construcción, tanto obras civiles como edificaciones, seguirá aportándole a la economía colombiana, dice Serfinco.

Por otra parte, hay elementos que si bien no sumarán en esa medida, tampoco le restarán impulso a la economía como en el 2014. Por un lado están las exportaciones, que se espera retomen un crecimiento ante una mejora de los socios comerciales del país y vuelvan a superar los 60.000 millones de dólares. También se prevé una recuperación de la industria, en tanto que la minería retomaría parte de su dinámica en 2015. Sin embargo, las cifras anteriores, consideradas aceptables en medio de la coyuntura global, están acompañadas de un ambiente de incertidumbre, local y externa.

En Colombia sigue la incertidumbre en torno a la reforma tributaria que se está discutiendo en el Congreso, por cómo cambiará la carga tributaria para las empresas y su impacto en la inversión. $Y$, lógicamente, el otro frente que incide en el país y sobre el que no se puede hacer gran cosa, es la coyuntura externa.

La recuperación de Estados Unidos y las decisiones de tasas de la Reserva Federal, la situación en Europa y el efecto de sus planes de estímulo, el enfriamiento de China y el panorama en el vecindario, son algunos de los elementos que crean incertidumbre. Aparte de la incertidumbre que genera el proceso en sí, para el país viene un reto aún mayor que las negociaciones, y es la estrategia con la cual va a hacer frente al posconflicto. Se necesitan cuantiosos recursos para el campo, la atención de los excombatientes, entre otros. El Gobierno cree que si este proceso se consolida y se llega un acuerdo, la economía podría crecer 1,5 puntos adicionales, cada año.

Los empresarios están divididos en sus opiniones sobre las perspectivas de la economía, pero hay consenso en su preocupación por el cambio en las reglas de juego, que puede significar la aprobación de la reforma tributaria que cursa en el Congreso. De acuerdo con los resultados de la última Encuesta de Opinión Conjunta, el 48,7 por ciento de los consultados dijeron que no tienen proyectos de inversión para el próximo año, en tanto que una porción 
similar opina lo contrario. Aseguran que el Gobierno no puede seguir cargando sobre los hombros del sector productivo las necesidades de financiamiento del Estado, a través del incremento de los impuestos. Agregan que si se mantiene el proyecto de ley que hace trámite en el Congreso se pone en riesgo la inversión y los planes de expansión de las empresas que están previstos para el 2015.

A través del Consejo Gremial Nacional, su presidente, Bruce Mac Master, el sector privado es partidario de que este año sea congelada la reforma tributaria y se concerté con los diferentes sectores una ley aplicable para los próximos tres años. Los gremios apoyan de manera incondicional los diálogos de paz, y reconocen que se llegarse a un acuerdo con las Farc, a partir del próximo año habrá una mejoría en las perspectivas de crecimiento y de la inversión nacional y extranjera, que ayudará a impulsar el desempeño del Producto Interno Bruto. Sin embargo, advierten que el costo del posconflicto no puede ser asumido por las mismas personas y las empresas que siempre han pagado impuestos. Asegura que una de las medidas que debe aplicar el Gobierno de manera inmediata es el recorte del gasto público, para aliviar la situación fiscal. Las proyecciones de crecimiento para el año 2015 varían entre 4,2\% y 4,7\% por ciento, mientras que hay confianza sobre la estabilidad de la inflación. En lo que sí hay preocupación empresarial es en la tasa de desempleo. Afirman que la tendencia descendente de la tasa de desocupación podría frenarse si el Gobierno insiste en la reforma tributaria y en la ley de reactivación de los recargos nocturnos y las horas extras, pues consideran que esto eleva los costos laborales, y afecta la contratación de personal.

De acuerdo con los supuestos del marco fiscal a mediano plazo, actualizado este año, en el 2015 la producción petrolera del país debe ser de 1 millón 29 mil barriles promedio diario. El cumplimiento de este pronóstico dependerá de que el país logre destrabar algunos cuellos de botella existentes como los problemas con licencias ambientales (solo ECOPETROL ha tenido que aplazar la producción de 16 mil barriles en promedio al día por estos temas).

El reto también estará en frenar los problemas de orden público y conflictos con las comunidades. De acuerdo con la Asociación Colombiana del Petróleo en el 2014 el sector ha perdido más de un billón de pesos por cuenta de los ataques a la infraestructura. Todo esto deberá solucionarse para permitirle a la industria crecer en un entorno de precios incierto.

En materia de producción de carbón la normalidad ganada en el 2014 en los puertos de Drummond y Cerrejón permite dar pie a proyecciones más optimista. De hecho, de acuerdo con la proyección del Ministro de Minas y Energía, Tomás González, el próximo año se puede superar la producción de 100 millones de toneladas, una cifra por encima de las 95 millones de toneladas que se aspiran producir.

Entre las metas que se trazó el Gobierno para este cuatrienio en materia de infraestructura está mantener el ritmo de construcción de doble calzada, en $300 \mathrm{~km}$ al año, para terminar en el 2018 con $1.200 \mathrm{~km}$. Para el 2015 continuará la adjudicación de concesiones de cuarta generación con 10 proyectos que suman $1.827 \mathrm{~km} \mathrm{y}$ demandan inversiones por 14,3 billones de pesos. También se seguirá con la evaluación y aprobación de las Asociaciones Público-Privadas (APP). Este año se espera sacar a licitación Ibagué-Cajamarca y concluir las aprobaciones de otras dos iniciativas que están maduras Malla vial del Meta y el tercer sector de la doble calzada Bogotá-Villavicencio. El próximo año se trabajaría en los avales para otras carreteras que están en factibilidad como: Caucásica -Planeta Rica-La Ye; Cereté -Lorica Toluviejo -Cruz del Viso, Cambao- Manizales-Mariquita Ibagué; San Roque - Paraguachón y La Paila - Cajamarca. En sector férreo a mediados del próximo año y después de 24 meses de obras, entrará en operación los tramos La Dorada (Caldas)-Chiriguaná (Cesar) y Bogotá-Belencito (Boyacá). Durante ese mismo año se empezará con las obras de la variante El Doctor-Mama toco, que iría por la detrás de la zona turística y permitiría movilizar carbón hacia el puerto de Santa Marta. Al mismo se desarrollarán importantes inversiones para los corredores férreos para pasajeros en Bogotá, que conectarán la Sabana con Soacha y Facatativa.

Para Jorge Enrique Gómez, presidente de la Lonja de Propiedad Raíz de Bogotá, "el sector inmobiliario se encuentra en uno de sus mejores momentos y de acuerdo con las proyecciones, en 2015 puede crecer en un 7.1\%. Este auge se debe a la construcción, la infraestructura y los programas de vivienda, lo que se refleja en el crecimiento sostenido de la economía colombiana". 


\title{
LA GLOBALIZACIÓN ECONÓMICA: IMPACTO EN EL TEJIDO HUMANO
}

\begin{abstract}
Luis Manuel Palomino Méndez - Elio Daniel Serrano Velasco - Edwin Omar Jaimes Rico
Para el 2015, las previsiones de Rafael Mejía, presidente participan, para tener vendedores y compradores con de la Sociedad de Agricultores de Colombia (SAC), indican capacidad económica, buscando fluidez en el proceso.
\end{abstract}

un crecimiento del 4,5 por ciento para el Producto Interno Bruto (PIB) total del país, mientras que el del sector agrario podrá ubicarse entre 3,8 y 4,0. "El café, por ejemplo, seguirá jalonando la economía del país", dijo Mejía. La avicultura, al igual que los cultivos de hortalizas y de papa, también serán otras de las actividades que darán el impulso a la economía agraria del país. En cuanto a la

inflación, el dirigente gremial destacó que también mantendría una estabilidad, por lo que no se esperarían mayores sobresaltos frente a las situaciones vividas durante este 2014.

\section{CONCLUSIONES:}

La globalización económica, es la respuesta dada a un momento histórico de desarrollo como conglomerado de habitantes de un planeta común, tiene una dinámica que seguramente terminara en la unificación de los mercados, en una moneda única, y la eliminación total de barreras arancelarias, impulsada, por el aporte tecnológico, la integración cultural, y la de homogenización de las necesidades a escala mundial.

El estado debe mantener un control del mercado de bienes y servicios, para evitar los desbordes de las grandes multinacionales, para ser proactivos a desmanes, en el tejido social, desde lo socio-económico. $\mathrm{Si}$ el Neoliberalismo, propende por la democracia, debe generar igualdad, para mantener un punto de equilibrio, que permita la calidad de vida del tejido social de una región.

El desarrollo económico, como dice su postulado teórico, debe permear todas las posibilidades de una comunidad, para que este desarrollo sea sostenible, que esté ligado al desarrollo humano, y se genera un sistema, que debe tener una dinámica que lo impulse.

La globalización económica, se basa en el intercambio comercial, para conseguir los recursos ausentes en una región, debe fortalecer el comercio y los países que
Alain Touraine (1994: 10) Globalización Neoliberal: Economía, Política y Cultura. Citado: http://rcci.net/globalizacion/2004/fg457.htm

Amschool.edu.sv (2011). Globalización de la Economía. Tomado:

http://soyunserpensanteenlaeconomiademipais.bl ogspot.com.co/2011/10/httpwwwamschooledusvp aescivicalaglobali.html

Ana María Ezcurra. (1998). ¿Qué es el neoliberalismo? Visión general. Síntesis de conclusiones. Tomado:

http://www.servicioskoinonia.org/relat/204.htm

BBVA Research, publicados en la revista PORTAFOLIO de $\begin{array}{llll}\text { Febrero } & 14 & \text { de } & 2013 .\end{array}$ http://www.portafolio.co/economia/finanzas/econo mia-colombiana-crecera-2013-201471894\#.leconomia-colombiana-crecera-2013201471894?\&_suid=146663284225803524810974380 7754.

Colombia frente a la globalización y la inserción internacional: ¿ ¿una segunda oportunidad sobre la tierra? 
ISSN: 1794-9920 - Enero - Julio

Volumen 16 Número: 1, Año: 2016 Págs. 71 - 85

Tema: Varios. Julio - Septiembre 1998. Páginas:

$28-40$

Departamento Administrativo Nacional de Estadística DANE. Fuente: www.banrep.gov.co. Tasas de interés. Indicador, Cifras, Fecha. DTF (EA) . 6,95\%. Junio 21.

Escuela Americana, "La Globalización Económica" (WEB) 4 de marzo de 2011, http://www.amschool.edu.sv/Paes/civica/la_global izaci\%C3\%B3n_econ\%C3\%B3mica.htm

Informe sobre Desarrollo Humano (1997). Publicado para el Programa de las Naciones Unidas para el Desarrollo (PNUD). Ediciones Mundi-Prensa. Tomado de https://derechoalaconsulta.files.wordpress.com/20 12/02/pnud-informe-1997-versic3b3n-integral.pdf.

Pedro Vivas Agüero (2013). Resumen. La Globalización de la Economía y o mundialización del capital. Email: D210060@unmsm.edu.pe.

Revista Dinero (08/21/2013), el ex presidente Cesar Gaviria. Apertura Económica. http://www.dinero.com/edicionimpresa/caratula/articulo/la-aperturaeconomica/182405

Sampedro, José Luis. (2002). El mercado y la globalización. Barcelona: Destino p. 65. 